\title{
TRUCK DRIVER TRAINING USING SIMULATION IN ENGLAND
}

\author{
Andrew M. Parkes \\ TRL \\ Driving Simulation Centre \\ Old Wokingham Road \\ Crowthorne, Berkshire, England \\ E-mail: aparkes@trl.co.uk
}

\begin{abstract}
Summary: The UK Department for Transport, on behalf of the Road Haulage Modernisation Fund, has established a research programme to determine the potential role of synthetic training in both ab initio license acquisition and also skills development in experienced drivers. TRL and EADS Dornier are commissioning an advanced full-motion-base truck simulator and developing bespoke courseware. The potential benefit of the system will be evaluated through a structured programme of training over 600 drivers. This paper reviews the current legislative framework in the UK and the European Union and discusses potential changes that will impact the training market. The paper then discusses the outline of the research programme and the technical capability of the system being developed.
\end{abstract}

\section{BACKGROUND}

The UK road haulage industry is a major contributor to the country's economy. This position is jeopardised by a looming crisis of recruitment of new drivers and the retention of existing ones. This situation could be exacerbated by European Union Directives on working time and training (not yet transposed for national legislation). These are likely to put more pressure on transport operators to recruit more drivers and to increase their fleet sizes.

Framework for road freight drivers detailed in the EU Working Time Directive

- $\quad$ a rest break where the working day is longer than 6 hours;

- a minimum rest period of 1 day a week;

- a maximum working week of 48 hours on average including overtime;

- 4 weeks' annual paid holiday; and

- that night workers must not work more than 10 hours in each 24-hour period

Source: EU Commission (2002)

The importance of road freight transport to Britain's economy and its current precarious position is highlighted by a number of recent publications. The UK road freight industry accounts for over 60,000 companies and employs over 600,000 people, 480,000 of whom are drivers (Mackinnon and Cooper, 2001). Issues which face the sector are its poor image, pressures faced by staff and management, in particular drivers, a high and increasing age profile of drivers, inadequate recruitment measures and skills shortages.

In addition to these, there can be no doubt of the hazardous nature of Heavy Goods Vehicle (HGV) driving (DfT, 2002). In Great Britain in 2001: 
- 14,813 HGVs were involved in injury accidents;

- there were 19,159 casualties in HGV road accidents in which there were:

- 575 fatalities (54 were occupants of the HGV - a fifth of fatalities were cyclists and pedestrians)

- 2,564 serious injuries, and

- 16,020 slight injuries.

The Training Directive stipulates that all persons wishing to drive Large Goods Vehicles LGVs in excess of 7.5 tonnes in a professional capacity will have to undergo training for, and obtain, a vocational Certificate of Professional Competence (CPC), further to the LGV licence. Currently, vocational training is only compulsory in France and the Netherlands.

Vocational training leading to the CPC will be kept, but the number of exemptions will be reduced and incentives will be introduced to reward drivers who undergo this training to have earlier access to larger vehicles. However, a requirement for full basic training leading to the $\mathrm{CPC}$ is likely to create short term problems in the labour market.

The total length of full basic training is 280 hours (12 weeks of 35 hours each). For full training each trainee driver must drive for at least 20 hours individually in a vehicle of the category concerned. Each driver may drive for a maximum of 8 hours of the 20 hours of individual training

“...on special terrain or on a top-of-the-range simulator so as to assess training in rational driving based on safety regulations, in particular with regard to vehicle handling in different road conditions and the way they change with different atmospheric conditions and the time of day or night." (European Parliament 2003, p. 24).

The new Directive goes even further. It opens the way for simulation to play a part in the practical element of the driving test. It states that the basic elements of the practical test must have a duration of at least 90 minutes. This practical test may be supplemented by a test taking place on special terrain or on a top-of-the-range simulator. "The duration of this optional test is not fixed. Should the driver undergo such a test, its duration may be deducted from the 90 minutes.... but the time deducted may not exceed 30 minutes" (op.cit. p. 25).

So, simulation is seen as a viable medium for ab initio training. However, the Training Directive is also concerned with the skill set of existing experienced drivers. A driver who has obtained his or her licence must undergo 35 hours of continuous training every 5 years. ".... Such periodic training may be provided, in part, on top-of-the-range simulators" (op.cit. p. 27).

According to the Directive, basic vocational training is divided into three areas:

1) Advanced training in rational driving based on safety rules,

2) Compliance with regulations, and

3) Health, safety, service and logistics. 
Of particular relevance to the issue of on-road and simulator training and simulator capability is the first of these areas, the syllabus for which is given below.

\section{Advanced training in rational driving based on safety regulations}

1. Technical characteristics: transmission system, curves relating to torque, power, and specific consumption of an engine, area of optimum use of revolution counter, gearbox ratio cover diagrams;

2. Braking, ABS, retarder, speed governor: operating principles, specific features of hydraulic vacuum servobrake circuit, limits to the use of brakes and retarder, combined use of brakes and retarder, use of braking systems on different types of road and under different atmospheric conditions, stopping and braking distance, making better use of speed and gear ratio, making use of vehicle inertia, using ways of slowing down and braking on downhill stretches, effects of weights and dimensions, controls and checks which are the responsibility of the driver, action in the event of failure;

3. Accident prevention: hazard perception, behaviour and vigilance on the part of the driver, factors contributing to road accidents, aggravating factors as regards lorries, driving hazards due to the state of the road surface and in particular how they change with atmospheric conditions, the time of day or night, driving on undulating roads and in tunnels, parking, effect of speed on the vehicle;

4. Consideration for other road users: awareness of other road users' intentions, specific factors as regards other road users (slow vehicles, light vehicles, two-wheeled vehicles, pedestrians), road safety measures;

5. Professional manoeuvres: identifying obstacles, preparation for manoeuvring, visibility, blind spots, swept area, behaviour and safety when manoeuvring, performance of professional manoeuvres;

6. Environment: optimisation of fuel consumption by applying know-how as regards each of the abovementioned points;

7. Loading: forces affecting vehicles in motion, use of gearbox ratios according to vehicle load and road profile, calculation of payload of vehicle or assembly, calculation of total volume, load distribution, consequences of overloading the axle, vehicle stability and centre of gravity, types of packaging and pallets, use of the tailgate lift (categories C1, C1E, C, CE only);

8. Securing: main categories of goods needing securing, clamping and securing techniques, use of securing straps, checking of securing devices, use of handling equipment, placing and removal of tarpaulins (categories $\mathrm{C} 1, \mathrm{C} 1 \mathrm{E}, \mathrm{C}, \mathrm{CE}$ only).

Source: EU COMMISSION (2001) 
In addition there are three points in the other two areas of direct relevance to in-vehicle/simulator training. These relate to:

- road traffic regulations: road signs, traffic restrictions and prohibitions, parking and stopping, use of special infrastructure, safety distance and stopping distance, specific speed limits for lorries/coaches, checks and penalties;

- ergonomic principles: movements and postures which pose a risk, physical position of the body, physical fitness (importance of the work of the muscles), posture and coordination of movements, handling exercises, personal protection;

- behaviour in an emergency situation: assessment of the situation, avoiding complications of an accident, summoning assistance, giving first aid to casualties, reaction in the event of fire, basic principles for the drafting of an accident report.

It is deemed necessary for professional drivers to refresh their knowledge and skills regularly, especially if their careers span several decades. Under the Directive the minimum for continuous training will be for five days every five years.

Except in France and the Netherlands, where there is at present training capacity for the 5 to $10 \%$ of new divers each year who wish to obtain the CPC, the introduction of compulsory basic and continuous training will require a large increase in capacity. The throughput of candidates may be assisted by the introduction of simulators for part of the training.

The DfT and the Road Haulage Forum has commissioned TRL to investigate the feasibility of a commercially available truck-driving simulator tailored to the needs of the UK road haulage industry. TRL have subcontracted EADS Dornier to provide a full-mission top-of-the-range simulator, with appropriate bespoke UK road databases and courseware.
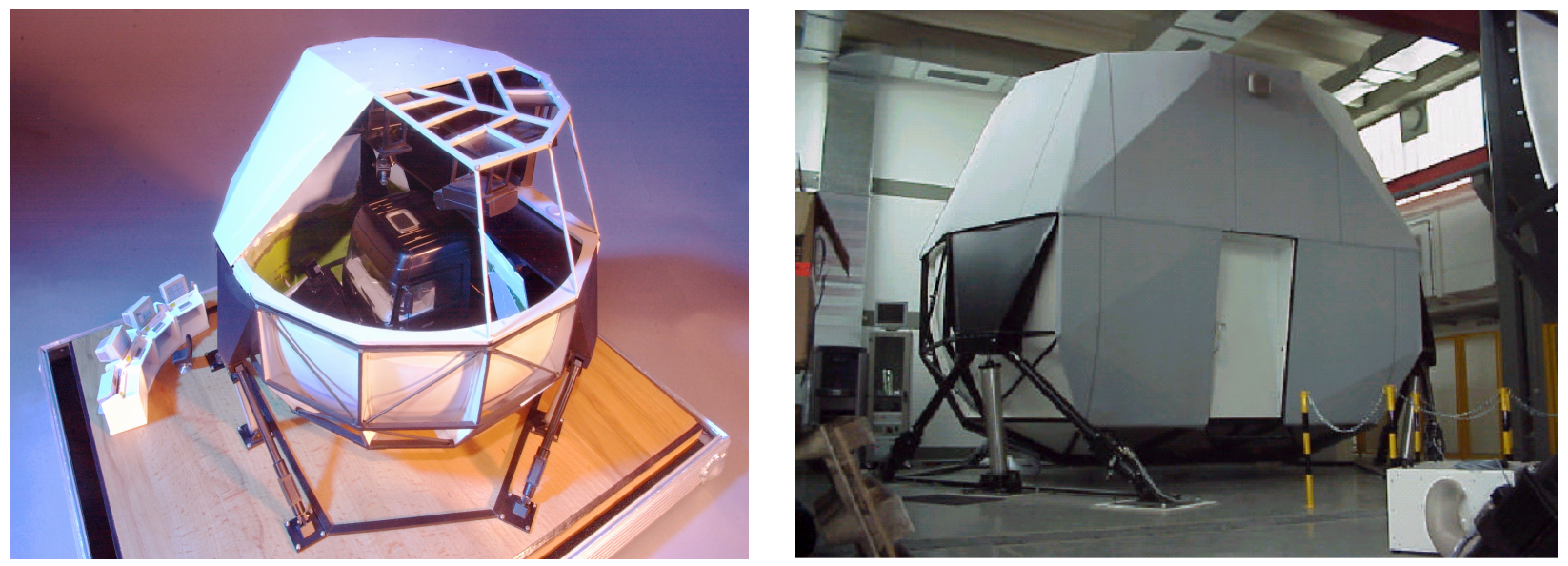

Figure 1. Scale model and exterior photograph of truck-driving simulator

The images above show a scale model of the simulator with an exposed canopy to reveal the orientation of truck cab, screen and projectors, and also an exterior photograph of the prototype system. The full system is aimed to be operational in October 2003 at the TRL headquarters in Crowthorne, England. 
During the period November 2003 to March 2004, over 600 drivers will take part in training and validation trials. Each driver will receive a combination of computer-based training, part-task simulation, and exercises in the full-mission simulator. The main focus will be to provide quantitative analysis of the efficiency and acceptability of training exercises provided within the synthetic environment. It is proposed that a curriculum of around 20 discrete exercises will be developed, and as far as practicable, objective scoring criteria for each will be generated. In the time available to each trainee, it will only be possible to expose him or her to a small set of the exercises. The exercises will be focussed on the key elements of rational driving course content described in the Directive.

The presentation of exercises will be balanced so that sufficient numbers of students are exposed to each one. The emphasis in this phase of the project is not on the general improvement of each individual student, but rather on the pedagogical value of the exercise itself. It would be expected that some exercises are more effective in the synthetic environment than others. Some may have little value to add over normal, behind-the-wheel training. It is even conceivable that some may have a negative effect, if the student is confused or if the task lacks realism.

This research phase has two main objectives. First, to expose a large number of students and freight companies to the potential of synthetic training. Second, to inform the DfT and RHMF how best synthetic training could be integrated into programmes of training and testing in good time to aid compliance with the EU Directives and help support such an important industry.

\section{ACKNOWLEDGEMENT}

The work reported here is supported by the Road Haulage Modernisation Fund (RHMF) and the Department for Transport (DfT) under contract PPAD 9/142/5. The views expressed are those of the authors and not necessarily those of the RHMF or the DfT. The author also acknowledges the large contribution of John Rutter of TRL for his review of training needs for the UK road freight industry.

\section{REFERENCES}

DfT. (2002). Road Accidents Great Britain: 2001. London: HMSO.

EU Commisssion. (2002). Proposal for a Directive of the European Parliament and of the Council on the training of professional drivers for the carriage of goods and passengers by road. .Available at europa.eu.int/eur-lex/en/com/pdf/2001/en_501PC0056.pdf

European Parliament. (2003). PE 330.876 (not yet published in European Journal).

FTA. (2001). Solving the skills shortage: Freight Transport Association. London.

Mackinnon, I. and Cooper, C. (2001). An assessment of skills needs in transport. Skills Dialogues: Listening to Employers. , Nottingham, UK: DfEE Publications. Available at www.nto-nc.org/newsite99/skillsforesight/transport.pdf 